\title{
Cell Type-Specific Development of NMDA Receptors in the Interneurons of Rat Prefrontal Cortex
}

\author{
Huai-Xing Wang' and Wen-Jun Gao*,' \\ 'Department of Neurobiology \& Anatomy, Drexel University College of Medicine, Philadelphia, PA, USA
}

In the prefrontal cortex, N-methyl-D-aspartic acid (NMDA) receptors (NMDARs) are critical not only for normal prefrontal functions but also for the pathological processes of schizophrenia. Little is known, however, about the developmental properties of NMDARs in the functionally diverse sub-populations of interneurons. We investigated the developmental changes of NMDARs in rat prefrontal interneurons using patch clamp recording in cortical slices. We found that fast-spiking (FS) interneurons exhibited properties of $\boldsymbol{\alpha}$-amino3-hydroxy-5-methyl-4-isoxazolepropionic acid (AMPA) and NMDA currents distinct from those in regular spiking (RS) and lowthreshold spiking (LTS) interneurons, particularly during the adolescent period. In juvenile animals, most (73\%) of the FS cells demonstrated both AMPA and NMDA currents. The NMDA currents, however, gradually became undetectable during cortical development, with most (74\%) of the FS cells exhibiting no NMDA current in adults. In contrast, AMPA and NMDA currents in RS and LTS interneurons were relatively stable, without significant changes from juveniles to adults. Moreover, even in FS cells with NMDA currents, the NMDA/AMPA ratio dramatically decreased during the adolescent period but returned to juvenile level in adults, compared with the relatively stable ratios in RS and LTS interneurons. These data suggest that FS interneurons in the prefrontal cortex undergo dramatic changes in glutamatergic receptors during the adolescent period. These properties may make FS cells particularly sensitive and vulnerable to epigenetic stimulation, thus contributing to the onset of many psychiatric disorders, including schizophrenia.

Neuropsychopharmacology (2009) 34, 2028-2040; doi: I0.1038/npp.2009.20; published online 25 February 2009

Keywords: cerebral cortex; GABAergic interneurons; glutamatergic receptors; psychiatric disorders; schizophrenia

\section{INTRODUCTION}

Gamma-aminobutyric acid (GABA)-ergic interneurons are important for concerted interactions between inhibitory and excitatory circuits and constitute a critical substrate for synchronous neural activity in the brain (Whittington and Traub, 2003; Hasenstaub et al, 2005; Buzsaki et al, 2007). $\mathrm{N}$-methyl-D-aspartic acid receptors (NMDARs), on the other hand, play an essential role in shaping the integrative properties and spike timing in interneurons (Lei and McBain, 2002; Maccaferri and Dingledine, 2002). In the past decade, both NMDARs and inhibitory neurons in the prefrontal cortex (PFC) have become increasingly important in the study of schizophrenia (Mohn et al, 1999; Kristiansen et al, 2006; Kristiansen et al, 2007; Beneyto and Meador-Woodruff, 2008; Lewis and Gonzalez-Burgos, 2008). The long-standing dopamine hypothesis has been challenged by a hypofunction hypothesis of both NMDARs and inhibition (Olney and Farber, 1995; Moghaddam and

\footnotetext{
*Correspondence: Dr W-J Gao, Department of Neurobiology and Anatomy, Drexel University College of Medicine, Room 243, 2900 Queen Lane, Philadelphia, PA 19129, USA, Tel: + I 215 991 8907, Fax: + I 215843 9802, E-mail: wgao@drexelmed.edu Received 14 April 2008; revised 27 January 2009; accepted 29 January 2009
}

Jackson, 2003; Coyle, 2006; Lindsley et al, 2006). NMDAR antagonists, such as phencyclidine, MK-801, and ketamine, can produce a range of symptoms remarkably similar to those found in patients with schizophrenia (Javitt and Zukin, 1991; Krystal et al, 1994; Lahti et al, 1995). These compounds can also cause selective damage to a subpopulation of interneurons in the PFC in animal models of schizophrenia (Kinney et al, 2006; Rujescu et al, 2006; Behrens et al, 2007; Harte et al, 2007). On the basis of these observations, a potential NMDAR hypofunction mechanism has been suggested to contribute to the pathogenesis of schizophrenia (Olney and Farber, 1995; Morris et al, 2005). A key point of this hypothesis is that NMDAR antagonism may result in NMDAR hypofunction in selected GABAergic interneurons, which in turn leads to disinhibition of glutamatergic excitation.

This hypothesis is intriguing, but direct evidence of how NMDAR antagonists selectively act on specific populations of PFC interneurons remains unclear. In fact, little is known regarding the properties of NMDARs in cortical interneurons (Blatow et al, 2005). Some evidence suggests that NMDAR-mediated excitatory responses exist in cortical interneurons, but these findings are controversial. For instance, Thomson (1997) reported the existence of NMDARs in both pyramidal neurons and interneurons in 
rat neocortex, whereas other studies have suggested that interneurons lack NMDAR-mediated responses (Ling and Benardo, 1995; Angulo et al, 1999; Goldberg et al, 2003). Kinney et al (2006) recently demonstrated rich NR2A subunits in cultured PV-ir interneurons. However, it is not clear whether NMDAR subunits in the prefrontal interneurons in adult animals are analogous to those expressed in cultured cells. Furthermore, no information is available regarding the receptor subtypes expressed by functionally distinct populations of interneurons in the neocortex. Because both interneurons (Gao et al, 2000; Tseng and O'Donnell, 2007) and NMDARs (Kumar and Huguenard, 2003; Liu et al, 2004) undergo dramatic changes during cortical development and most psychiatric disorders progress during peri-adolescent period (Spear, 2000; Lewis et al, 2004), it is therefore imperative to systematically study the development of NMDARs on diverse functionally identified interneurons in the PFC.

\section{MATERIALS AND METHODS}

\section{Brain Slice Preparation and Physiological Recording}

The animals were cared for under NIH animal use guidelines, and the experimental protocol was approved by the Institutional Animal Care and Use Committee at Drexel University College of Medicine. Rats were divided into three age groups: juvenile (p15-28), adolescent (p3149), and adult (p88-108), based on the criteria described previously (Spear, 2000; Tseng and O’Donnell, 2007). The animals were deeply anesthetized with Euthasol $(0.2 \mathrm{ml} / \mathrm{kg}$, i.p.), rapidly perfused with ice-cold Ringer solution, and decapitated with a guillotine. The brains were quickly removed and placed in ice-cold $\left(<4^{\circ} \mathrm{C}\right)$ sucrose solution containing (mM): $\mathrm{KCl} 2.5, \mathrm{NaH}_{2} \mathrm{PO}_{4} 1.25, \mathrm{NaHCO}_{3} 26, \mathrm{CaCl}_{2}$ 0.5 , and $\mathrm{MgSO}_{4} 7.0$, sucrose 213 , and aerated with $95 \% \mathrm{O}_{2}$ and $5 \% \mathrm{CO}_{2}$. A block of neocortex containing medial PFC (PrL, Paxinos and Watson, The Rat Brain in Stereotaxic Coordinates, 2005) was trimmed and glued onto the stage of Vibratome (Vibratome Co., St Louis, MO). Horizontal brain slices with a thickness of $300 \mu \mathrm{m}$ were incubated in oxygenated Ringer's solution at $35^{\circ} \mathrm{C}$ for $1 \mathrm{~h}$. Ringer's solution contains the following ingredients (in $\mathrm{mM}$ ): $\mathrm{NaCl}$ 128, $\mathrm{KCl} 2.5, \mathrm{NaH}_{2} \mathrm{PO}_{4} 1.25, \mathrm{CaCl}_{2} 2, \mathrm{MgSO}_{4} 1, \mathrm{NaHCO}_{3} 26$, and dextrose 10, pH 7.4. The slices were kept at room temperature and then transferred to a submerged chamber for recording (Gao et al, 2001, 2003; Gao and GoldmanRakic, 2003; Gao, 2007). Whole-cell patch clamp recordings were conducted in the PFC slices through an upright microscope (Olympus BX61; Olympus Optics, Japan) equipped with a digital video camera system. The recordings were conducted at $\sim 36^{\circ} \mathrm{C}$. Resistance of the recording pipette ( $1.2 \mathrm{~mm}$ borosilicate glass) was 9-12 $\mathrm{M} \Omega$. Tips of the recording pipettes were first filled with $\mathrm{K}^{+}$-gluconatebased intracellular solution and then back-filled with $\mathrm{Cs}^{+}{ }_{-}$ containing solution. The $\mathrm{K}^{+}$-gluconate solution contains (in $\mathrm{mM}$ ): $\mathrm{K}^{+}$-gluconate $120, \mathrm{KCl} 6, \mathrm{ATP}-\mathrm{Mg} \mathrm{4}, \mathrm{Na}_{2} \mathrm{GTP} 0.3$, EGTA 0.1, HEPES 10, and 0.3\% biocytin, pH 7.3, $310 \mathrm{mOsm}$, whereas the $\mathrm{Cs}^{+}$solution contains (in $\mathrm{mM}$ ): Cs-gluconate 120, lidocaine 5 (QX-314), $\mathrm{CsCl}_{2}$ 6, ATP-Mg 1, $\mathrm{Na}_{2} \mathrm{GTP} 0.2$, HEPES 10, and $0.3 \%$ biocytin at $\mathrm{pH} 7.3$ (adjusted with $\mathrm{CsOH})$. With this strategy, we were able to record the action potentials (APs) immediately after Giga-seal formation. The relative locations of all recorded cells in individual brain slices were documented for further morphological identification after immunostaining (see next section). This step is important for neuronal classification of the tested interneurons. The excitatory synaptic responses of these cells were evoked by stimulating layer $2 / 3$ with a bipolar electrode placed $\sim 200-500 \mu \mathrm{m}$ away (single pulse, $0.1 \mathrm{~ms}$, $40-400 \mu \mathrm{A}, 0.1 \mathrm{~Hz})$ in the presence of $\mathrm{GABA}_{\mathrm{A}}$ antagonist picrotoxin $(50 \mu \mathrm{M}$; Sigma-Aldrich, St Louis, MO). Alphaamino-3-hydroxy-5-methyl-4-isoxazolepropionic acid receptor (AMPAR)-mediated currents were recorded at $-70 \mathrm{mV}$, whereas NMDAR-mediated currents were recorded at $+60 \mathrm{mV}$ under conditions of bath-applied both picrotoxin and AMPAR antagonist CNQX (6-cyano-7nitroquinoxaline-2,3-dione) $20 \mu \mathrm{M}$; (Sigma-Aldrich). NMDAR currents were confirmed by bath application of the NMDAR antagonist D-(-)-2-amino-5-phosphonopentanoic acid (D-AP5, $50 \mu \mathrm{M})$. The stimulus intensity applied to individual neurons was adjusted to produce an AMPA receptor-mediated current at about $50-100 \mathrm{pA}$ at $-70 \mathrm{mV}$. The electric signals were amplified and filtered at $2 \mathrm{kHz}$ in voltage clamp mode with MultiClamp 700B (Molecular Devices, Union City, CA). The data were acquired at sampling intervals of $20-50 \mu$ s through a DigiData $1322 \mathrm{~A}$ (data acquisition system) and pCLAMP 9.2 software (Molecular Devices). Access resistances were continuously monitored with an injection of $-100 \mathrm{pA}$ current for $100 \mathrm{~ms}$ during recording. Only cells exhibiting a stable membrane potential without injection of holding current were used for the analysis.

\section{Histological and Morphological Analyses}

All slices with recorded neurons were preserved for biocytin immunostaining as reported previously (Gao et al, 2003; Gao, 2007). Slices were fixed in $4 \%$ paraformaldehyde until immunocytochemical processing occurred. The slices were placed in $3 \% \mathrm{H}_{2} \mathrm{O}_{2}$ for $30 \mathrm{~min}$ to block the endogenous horseradish peroxidase. After thorough rinsing, $\mathrm{ABC}$ (Vector Laboratories, CA, US) reactions were conducted overnight, followed by the $\mathrm{Ni}$-3,3-diaminobenzidine reaction. The slices were directly mounted from $0.2 \mathrm{mM}$ phosphate buffer ( $\mathrm{pH}$ 7.4) and covered with water-soluble mounting media. All labeled neurons were photographed and matched with their firing patterns.

\section{Data Analysis}

All recorded neurons were initially identified as interneurons by their morphological characteristics, such as small and round, oval, or spindle-like cell bodies and multipolar or bipolar dendrites, under the videomicroscope with infrared-differential interference contrast optics. Identities of the recorded neurons were further confirmed by several criteria, including biocytin-labeled morphologies, firing patterns, amplitudes of fast afterhyperpolarization (fAHP), half-width of APs, and spontaneous postsynaptic potentials (sPSPs) (see Figure 1). With these criteria, the interneurons recorded were easily distinguished from pyramidal neurons, which usually occupy larger pyramidal soma and piaoriented apical dendrites. The membrane time constants 

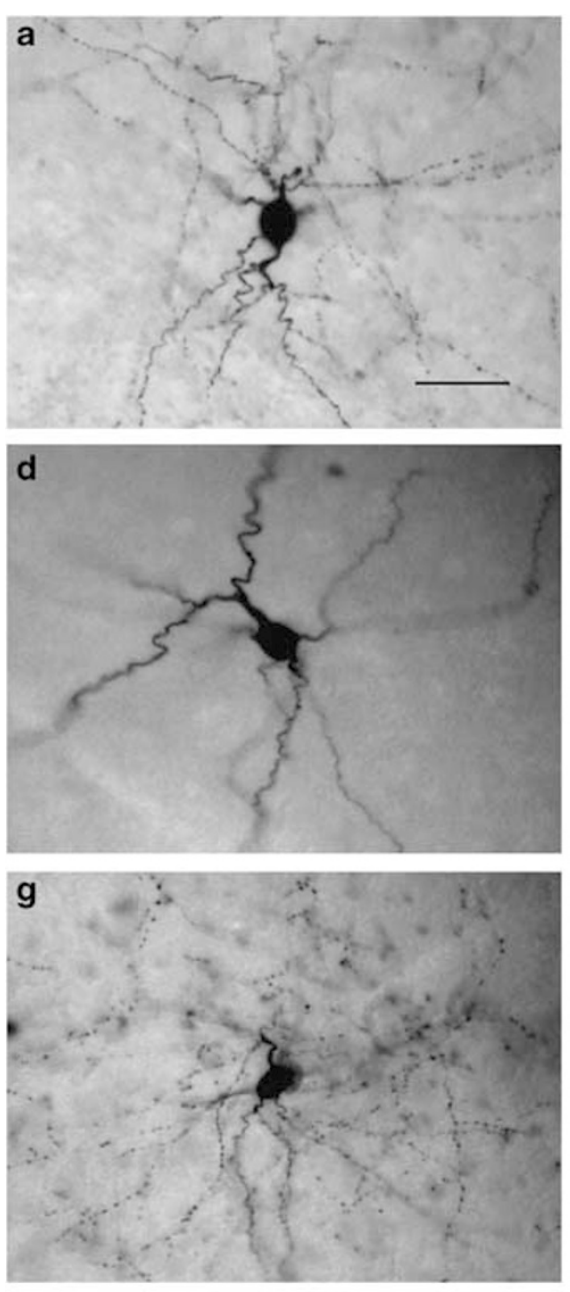

b

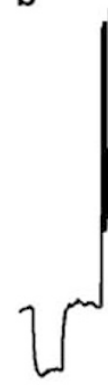

e<smiles>CCCCC</smiles>

h

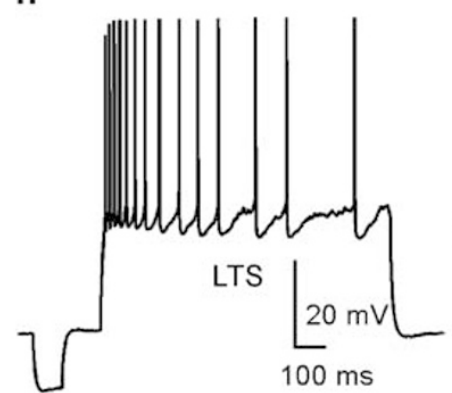

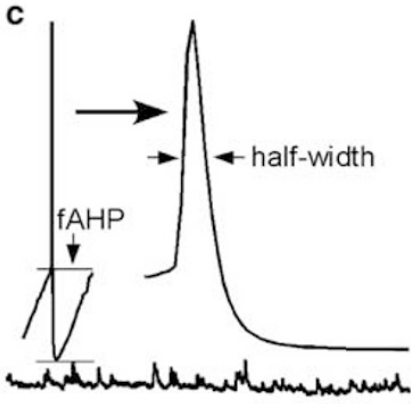

f

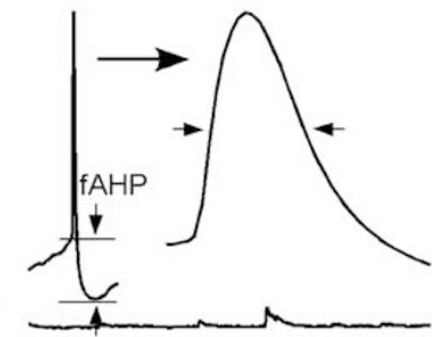

i

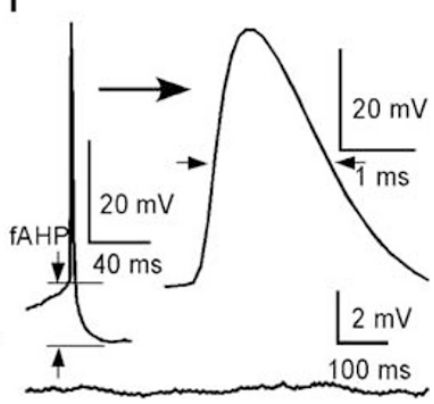

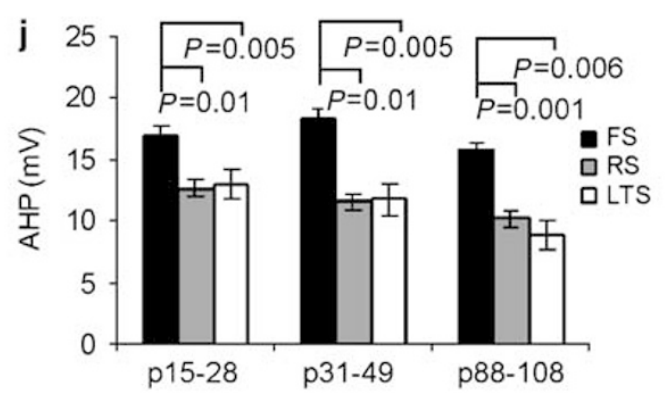

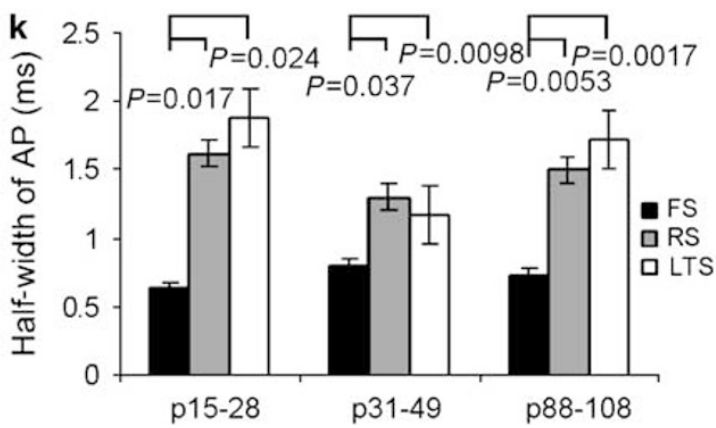

Figure I Identification of prefrontal cortical interneurons. (a-c) sample of FS interneuron. (a) Basket-like interneuron. Scale bar $=20 \mu \mathrm{m}$ for $(\mathrm{a}, \mathrm{d}, \mathrm{g})$. The FS cell was identified by its high-frequency firing of action potentials without adaptation, short half-width, rich spontaneous postsynaptic potentials, and large fAHP. (d-f) Sample of RS interneuron. Comparatively, RS neurons have adaptive firing, wider action potentials, relatively less spontaneous postsynaptic potentials, and smaller fAHP. ( $\mathrm{g}-\mathrm{i}$ ) Sample of LTS interneuron. LTS neurons are characterized by a short burst in the first 2-3 spikes, wider half-width, and smaller fAHP of action potentials. (j, k) summary graphs of fAHP and half-width of action potentials. FS cells exhibit significantly larger fAHP and shorter halfwidth than those of RS and LTS neurons.

were analyzed by fitting the membrane voltage transient induced by a $0.1 \mathrm{nA}$ negative current pulse of $150 \mathrm{~ms}$ duration (Figure $1 \mathrm{~b}, \mathrm{e}$, and $\mathrm{h}$ ). The stimulation intensities were estimated from the artificial stimulus traces prior to the onset of the excitatory postsynaptic currents (EPSCs).

The EPSC amplitudes were measured by averaging 30 traces from the onset to the peak of EPSC with Clampfit 9.2 software (Molecular Devices). Only the neurons that produced stable EPSC for $5 \mathrm{~min}$ without rundown were used for further analysis of drug and stimulus effects. The decay time course, measured from $63 \%$ of the repolarization curve of a unitary EPSC, was fitted with a single exponential using standard exponential formula in Clampfit 9.2. The integrated EPSC area (charge transfer) of NMDAR- and AMPAR-mediated currents were measured with pCLAMP 9.2 and expressed in picocoulomb (pC) units. The 
contribution of the NMDAR subunit NR2B to overall NMDAR-mediated current was calculated from control measurements and with the application of ifenprodil, ie, (control trace-ifenprodil trace)/control $\times 100$. All data were presented as group measures with mean \pm standard error (SE) along with Student's $t$-test or ANOVA to examine statistical significance.

\section{RESULTS}

\section{Identifications of Recorded Interneurons in the mPFC}

The cortical GABAergic system comprises many different subclasses of interneurons, each having a unique phenotype defined by its morphological characteristics and electrophysiological properties (Kawaguchi, 1995; Freund and Buzsaki, 1996; Markram et al, 2004). Using the criteria described in Materials and Methods, we were able to unambiguously classify most (122 out of 145) of the recorded interneurons into three categories: fast-spiking (FS), regular spiking (RS), and low-threshold spiking (LTS) (Kawaguchi, 1995; Xiang et al, 1998; Gibson et al, 1999). The remaining 23 neurons excluded from the data set were either the ones that do not belong to the three aforementioned subtypes or the ones with difficulty to be classified because of the confounding effect of $\mathrm{Cs}^{+}$. These include one late spiking cell, six burst spike cells, eight irregular spiking cells, and eight cells that are difficult to classify. Most (109) of the 122 interneurons were recorded from layers 2-5 of the medial PFC, whereas 13 interneurons ( $1 \mathrm{FS}, 7 \mathrm{RS}$, and 5 LTS) were from layer 1.

As shown in Figure 1, FS interneurons were easily distinguished from RS and LTS interneurons because injection of depolarizing current pulse evoked a train of high frequency and non-adaptive spikes. The FS interneurons exhibited APs with short duration (half-width $\sim 0.71 \pm 0.12 \mathrm{~ms})$ and large fAHPs $(17.9 \pm 0.87 \mathrm{mV}$; Figure 1b). FS cells also exhibited characteristic sPSPs with high frequency and large amplitude. In contrast, both RS and LTS cells exhibited profound adapting firing with significantly wider APs (half-width $1.44 \pm 0.06 \mathrm{~ms}$ for RS and $1.78 \pm 0.10 \mathrm{~ms}$ for LTS cells; $P<0.001$ for either RS or LTS vs FS cells, and $P>0.05$ for RS vs LTS cells). These two types of cells also had significantly smaller fAHP $(11.2 \pm 0.62 \mathrm{mV}$ for RS and $11.4 \pm 0.70 \mathrm{mV}$ for LTS, $P<0.001$ compared with FS cells in all age groups). In addition, the FS interneurons had a significantly smaller input resistance relative to the other two cell types (input resistance $=190.7 \pm 10.37 \mathrm{M} \Omega$ for $F S, 246.1 \pm 15.70 \mathrm{M} \Omega$ for RS, and 247.2 $\pm 11.90 \mathrm{M} \Omega$ for LTS cells, $P<0.001$ for both RS and LTS compared with FS but without significant difference between RS and LTS cells, $P>0.05$; Figure 1). Interestingly, the input resistances of FS cells significantly increased by $16 \%$ in adolescence $(P<0.05)$, but decreased to juvenile level in adults $(P>0.05)$. The differences between RS and LTS interneurons were also substantial. LTS cells exhibited a clear short burst of 2-3 spikes (inter-spike interval $=8.82 \pm 0.32 \mathrm{~ms}$ ) or a LTS elicited from a hyperpolarized potential (Kawaguchi, 1995; Xiang et al, 1998; Gibson et al, 1999). We noted that the spike half-widths observed in the three cell types were broader than those described in previous reports (Kawaguchi, 1995; Gibson et al, 1999; Markram et al, 2004). The broadened spikes were likely derived from $\mathrm{Cs}^{+}$included in the recording pipette, although the pipette tips were filled with $\mathrm{K}^{+}$ solution. These alterations, however, would not affect our conclusion because the spike widths observed in RS and LTS were still significantly shorter than those in pyramidal neurons recorded under same conditions $(2.62 \pm 0.30 \mathrm{~ms}$, $n=26, P<0.05)$. Nevertheless, the spike amplitude of these interneurons and the resting membrane potentials were similar, without significant difference among the three cell types (Figure 1; Table 1).

\section{NMDARs in FS Cells Gradually Lost during Cortical Development and Majority of the FS Cells Exhibiting no NMDAR-Mediated Currents in Adult Rat PFC}

Although numerous studies have reported a developmental change in NMDARs from different cortical regions, most of the studies have focused on NMDAR functions in pyramidal cells (Monyer et al, 1994; Kumar and Huguenard, 2003; Liu et al, 2004). Little is known regarding the NMDARs in cortical interneurons (Blatow et al, 2005). To record the AMPA and NMDA currents, we applied whole-cell patch clamp to individual interneurons. The AMPAR-mediated EPSCs were recorded at $-70 \mathrm{mV}$ with extracellular stimulation applied in layer $2 / 3$ in the presence of picrotoxin $(50 \mu \mathrm{M})$, whereas the NMDAR-mediated EPSCs were documented at $+60 \mathrm{mV}$ by blocking both AMPA (CNQX, $20 \mu \mathrm{M})$ and $\mathrm{GABA}_{\mathrm{A}}$ channels. Interestingly, we found that both AMPAR- and NMDAR-mediated EPSCs in the FS interneurons exhibited distinct properties and dramatic changes during prefrontal cortical development, particularly in adolescents. About one-fourth $(3 / 11,27.3 \%)$ of the FS interneurons in juveniles exhibited no NMDARmediated current, although the AMPAR-mediated currents were prominent (Figure 2). The number of FS cells without NMDAR-mediated currents gradually increased during the cortical development. It reached $57.1 \%$ in adolescents and $73.9 \%$ in adults. Figure 2 shows the two types of FS cells: FS interneurons with and without NMDAR-mediated currents. It is clear that the number of FS cells without NMDARmediated currents increased significantly in the adult animals with only about $26.1 \%$ of the FS cells recorded exhibiting NMDA current $(6 / 23,26.1 \%, P<0.01)$. On the other hand, despite the difference in NMDAR-mediated currents, many other properties such as resting membrane potential, input resistance, AP half-width, membrane time constant, AMPAR-mediated EPSC rise-time and decay were generally similar between the FS cells with and without NMDA-EPSCs (Table 1). We found only one exception: the FS interneurons without NMDA showed significantly smaller fAHP $(-17.9 \pm 0.87 \mathrm{mV}$ in FS cells with NMDA current $v s-13.1 \pm 0.75 \mathrm{mV}$ in FS cells without NMDA current, $P<0.01)$. Moreover, the AMPAR-EPSC decay was also slower in the FS cells with NMDA current $(4.67 \pm 0.50 \mathrm{~ms})$ compared with the FS neurons without NMDA current $(3.64 \pm 0.19 \mathrm{~ms}, P<0.05)$ during the adolescent period. The overall decays averaged from all age groups were not statistically different though $(4.45 \pm 0.33 \mathrm{~ms}$ in FS cells with NMDA current vs $3.98 \pm 0.49$ in FS cells without NMDA current, $P=0.351)$. Likewise, the FS interneurons with and without NMDA current in adolescents had higher 
Table I Membrane and EPSC Properties of Prefrontal Interneurons

\begin{tabular}{|c|c|c|c|c|c|c|c|c|c|c|c|c|}
\hline \multirow{2}{*}{ Interneuron type } & \multicolumn{3}{|c|}{ FS with NMDA current } & \multicolumn{3}{|c|}{ FS without NMDA current } & \multicolumn{3}{|c|}{ RS } & \multicolumn{3}{|c|}{ LTS } \\
\hline & $\begin{array}{l}\text { pl 5-28 } \\
(n=8)\end{array}$ & $\begin{array}{l}\text { p3 I-49 } \\
(n=6)\end{array}$ & $\begin{array}{l}\text { p88-108 } \\
(n=6)\end{array}$ & $\begin{array}{l}\text { pl 5-28 } \\
(n=3)\end{array}$ & $\begin{array}{l}\text { P3 I-49 } \\
(n=8)\end{array}$ & $\begin{array}{l}\text { p88-108 } \\
(n=17)\end{array}$ & $\begin{array}{l}p 15-28 \\
(n=I I)\end{array}$ & $\begin{array}{l}\text { p3 I-49 } \\
(n=9)\end{array}$ & $\begin{array}{l}\text { p88-108 } \\
(n=18)\end{array}$ & $\begin{array}{l}p \mid 5-28 \\
(n=18)\end{array}$ & $\begin{array}{l}\text { p3 I-49 } \\
(n=5)\end{array}$ & $\begin{array}{l}p 88-108 \\
(n=14)\end{array}$ \\
\hline Animal age (days) & $20.1 \pm 1.33$ & $40.8 \pm 2.70$ & $96.0 \pm 3.16$ & $20.0 \pm 2.08$ & $39.5 \pm 2.02$ & $96.1 \pm 2.37$ & $21.8 \pm 1.75$ & $41.0 \pm 2.58$ & $94.1 \pm 1.27$ & $23.6 \pm 1.14$ & $36.2 \pm 2.31$ & $96.2 \pm 1.27$ \\
\hline $\operatorname{RMP}(m V)$ & $64.6 \pm 1.35$ & $63.1 \pm 2.54$ & $69.8 \pm 1.66$ & $63.8 \pm 1.39$ & $61.2 \pm 2.86$ & $68.0 \pm 1.70$ & $57.8 \pm 1.35$ & $65.4 \pm 2.02$ & $65.0 \pm 1.62$ & $63.9 \pm 1.37$ & $67.7 \pm 3.29$ & $63.6 \pm 1.94$ \\
\hline $\mathbb{R}(M \Omega)$ & $179.1 \pm 16.76$ & $207.4 \pm 24.95 *$ & $189.9 \pm 14.8$ & $181.7 \pm 24.762$ & $211.9 \pm 19.28 *$ & $178.9 \pm 13.12$ & $257.3 \pm 28.9$ & $225.0 \pm 12.8$ & $250.3 \pm 20.2$ & $263.4 \pm 13.3$ & $240.9 \pm 35.8$ & $216.5 \pm 26.4$ \\
\hline AHP (mV) & $\mid 6.9 \pm 0.81$ & $|8.3| \pm 2.84 *$ & $15.7 \pm 0.48$ & $14.2 \pm 1.04$ & $12.8 \pm 1.07 * \$$ & $10.9 \pm 2.36$ & $12.7 \pm 1.02$ & $11.6 \pm 1.75$ & $10.2 \pm 0.95$ & $13.0 \pm 0.93$ & $11.7 \pm 1.08$ & $8.91 \pm 1.12$ \\
\hline AP I/2 width (ms) & $0.63 \pm 0.13$ & $0.8 \pm 0.4$ & $0.73 \pm 0.20$ & $0.65 \pm 0.05$ & $0.64 \pm 0.07$ & $0.50 \pm 0.04$ & $1.62 \pm 0.14$ & $1.30 \pm 0.12$ & $1.50 \pm 0.09$ & $1.88 \pm 0.12$ & $1.18 \pm 0.06$ & $1.72 \pm 0.16$ \\
\hline $\begin{array}{l}\text { Membrane time constant } \\
\text { (ms) }\end{array}$ & $8.62 \pm 1.65$ & $8.25 \pm 1.11$ & $6.60 \pm 0.81$ & $6.50 \pm 0.86$ & $7.44 \pm 0.80$ & $6.22 \pm 0.31$ & $18.89 \pm 2.34$ & $9.07 \pm 0.80$ & $10.88 \pm 1.30$ & $18.40 \pm 1.19$ & $9.32 \pm 1.07$ & $14.65 \pm 1.38$ \\
\hline AMPA amplitude (pA) & $59.8 \pm 11.1$ & $99.7 \pm 14.9$ & $66.9 \pm 11.4$ & $74.7 \pm 10.1$ & $59.5 \pm 14.0$ & $98.2 \pm 14.6$ & $46.7 \pm 8.70$ & $52.3 \pm 3.92$ & $51.4 \pm 5.76$ & $51.8 \pm 4.63$ & $72.2 \pm 1.70$ & $40.1 \pm 4.50$ \\
\hline AMPA 63\% decay (ms) & $3.90 \pm 0.53$ & $4.67 \pm 0.50 *$ & $4.40 \pm 0.77$ & $6.49 \pm 0.01^{\$}$ & $3.64 \pm 0.19 * \$$ & $3.77 \pm 0.58$ & $8.61 \pm 0.34$ & $7.86 \pm 0.71$ & $7.66 \pm 0.31$ & $6.90 \pm 0.84$ & $7.53 \pm 0.69$ & $9.50 \pm 0.84$ \\
\hline AMPA charge $(p C)$ & $0.75 \pm 0.14$ & $1.29 \pm 0.12$ & $0.53 \pm 0.13$ & $1.08 \pm 0.01$ & $0.53 \pm 0.09$ & $0.70 \pm 0.09$ & $1.07 \pm 0.15$ & $0.66 \pm 0.19$ & $0.88 \pm 0.14$ & $1.17 \pm 0.10$ & $1.21 \pm 0.13$ & $1.21 \pm 0.18$ \\
\hline $\begin{array}{l}\text { AMPA } 20-80 \% \text { rise time } \\
\text { (ms) }\end{array}$ & $0.80 \pm 0.05$ & $0.53 \pm 0.22$ & $0.52 \pm 0.06^{\#}$ & $1.03 \pm 0.01$ & $0.78 \pm 0.10$ & $0.83 \pm 0.08^{\#}$ & $1.35 \pm 0.15$ & $1.41 \pm 0.10$ & $1.35 \pm 0.07$ & $1.51 \pm 0.07$ & $1.39 \pm 0.07$ & $1.21 \pm 0.13$ \\
\hline NMDA amplitude (pA) & $48.8 \pm 8.71$ & $37.9 \pm 6.17$ & $33.6 \pm 1.56$ & & & & $47.2 \pm 10.6$ & $51.4 \pm 16.4$ & $50.9 \pm 7.03$ & $42.5 \pm 4.97$ & $51.9 \pm 8.21$ & $48.1 \pm 7.02$ \\
\hline NMDA 63\% decay (ms) & $39.8 \pm 3.05$ & $32.9 \pm 4.90$ & $21.6 \pm 3.05$ & & & & $44.7 \pm 4.35$ & $41.1 \pm 3.00$ & $44.6 \pm 3.96$ & $67.4 \pm 4.89$ & $56.5 \pm 6.77$ & $48.9 \pm 5.29$ \\
\hline NMDA charge $(p C)$ & $2.44 \pm 0.45$ & $1.82 \pm 037$ & $1.30 \pm 0.22$ & & & & $2.79 \pm 0.27$ & $2.25 \pm 0.17$ & $2.41 \pm 0.23$ & $3.34 \pm 0.54$ & $3.61 \pm 0.75$ & $3.42 \pm 0.50$ \\
\hline $\begin{array}{l}\text { NMDA 20-80 rise time } \\
\text { (ms) }\end{array}$ & $2.44 \pm 0.14$ & $2.73 \pm 0.07$ & $2.49 \pm 0.38$ & & & & $3.19 \pm 0.25$ & $2.93 \pm 0.25$ & $3.07 \pm 0.19$ & $3.54 \pm 0.13$ & $3.22 \pm 0.39$ & $3.14 \pm 0.14$ \\
\hline NMDA/AMPA peak ratio & $0.90 \pm 0.19$ & $0.33 \pm 0.12$ & $0.77 \pm 0.2$ & & & & $0.74 \pm 0.05$ & $0.83 \pm 0.22$ & $0.97 \pm 0.12$ & $1.33 \pm 0.23$ & $1.17 \pm 0.47$ & $1.03 \pm 0.14$ \\
\hline NMDA/AMPA area ratio & $2.71 \pm 0.98$ & $1.30 \pm 0.20$ & $2.45 \pm 1.31$ & & & & $1.64 \pm 0.38$ & $1.86 \pm 0.43$ & $2.13 \pm 0.28$ & $2.59 \pm 0.27$ & $2.38 \pm 0.47$ & $2.40 \pm 0.36$ \\
\hline
\end{tabular}

$* P<0.05$ between adolescents (p3I-49) and juveniles (p I5-28) as well as between adolescents (p3I-49) and adults (p88-108) in both FS cells with and without NMDA current.

${ }^{\$} P<0.05$ between FS with and without NMDA current in adolescents $(\mathrm{p} 31-49)$.

${ }^{\#} P<0.05$ between FS cells with and without NMDA current in adults ( $\left.\mathrm{p} 88-108\right)$ 

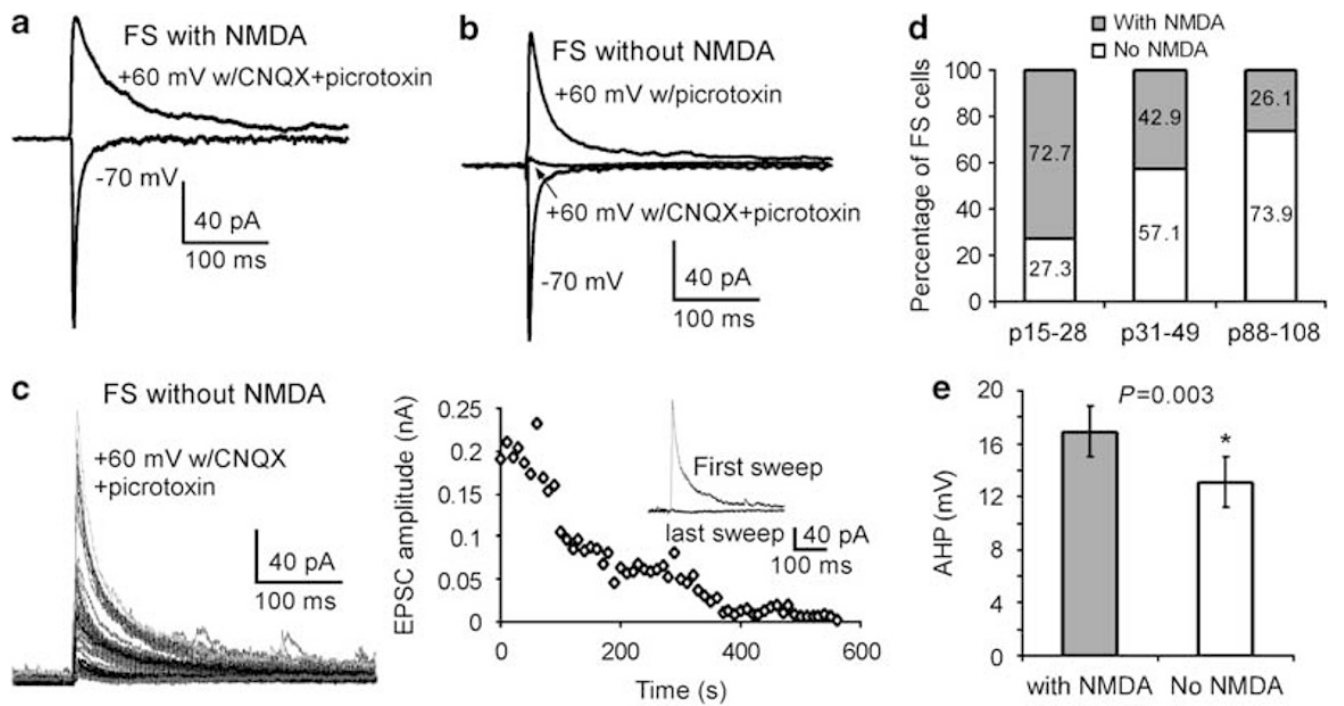

Figure 2 FS interneurons with and without NMDAR-mediated currents in the PFC. (a, b) Some FS interneurons express NMDA current at positive potentials $+60 \mathrm{mV}(\mathrm{a})$, whereas others exhibit no NMDAR-mediated current, although AMPA-mediated currents were prominent at both -70 and + $60 \mathrm{mV}$ (b). (c) Raw data sample of a FS cell without NMDA and measurement of the peak amplitudes of the AMPAR-mediated currents, which were gradually blocked by bath-applied CNQX. (d) Summary graph showing the percentage of FS interneurons in three age groups ( $n=48$ ). In juveniles, about $72 \%$ of the FS cells contain NMDAR-mediated currents that gradually reduce to about $26 \%$ in adult. Overall, a majority (58.3\%) of the FS interneurons tested do not have detectable NMDAR-mediated current. (e) FS cells containing NMDARs exhibit significantly larger fAHP compared with those without NMDARs $(* P=0.003)$.

input resistances compared with those FS interneurons in juvenile and adult animals, but there was no difference between the two groups $(207.4 \pm 24.95$ in FS cells with NMDA current $v s 211.9 \pm 19.28$ in FS cells without NMDA current, $P=0.807)$. These data are consistent with numerous previous studies conducted in different brain regions with either electron microscope (Nyiri et al, 2001) or physiological recordings (Sah et al, 1990; Perouansky and Yaari, 1993; Morin et al, 1996; Maccaferri and Dingledine, 2002). These data indicated that although the membrane time constants were different in individual cell types, the NMDA current changes in the FS cells are not attributable to the passive membrane properties because the changes in membrane time constants appeared to be age independent in the FS cells with NMDA currents (see Table 1).

\section{Cell Type-Specific Changes of AMPARs and NMDARs during Cortical Development}

Compared with the dramatic change of NMDARs in FS cells, glutamatergic receptors on the RS and LTS cells were relatively stable from juvenile to adult. As shown in Figure 3, AMPA-EPSCs in FS neurons had significantly faster risetime $(20-80 \%)$ compared with those in RS and LTS cells $(0.62 \pm 0.06 \mathrm{~ms}$ in FS $v s \quad 1.28 \pm 0.06$ in RS cells and $1.40 \pm 0.05$ in LTS cells; $P<0.001)$, consistent with previous studies (Hestrin, 1993; Koh et al, 1995; Angulo et al, 1997; Zhou and Hablitz, 1998). The rise-time in FS cells is age dependent with adult animals exhibiting an even faster risetime $\left(R^{2}=0.415 ; P<0.005\right)$. In contrast, the RS and LTS cells did not show significant changes among the three age groups $\left(R^{2}=0.061\right.$ for RS and $R^{2}=0.0004$ for LTS cells; $P>0.05$ for both). The adult LTS cells seemed to be an exception though, with a significantly faster rise-time in adults compared with juveniles $(1.51 \pm 0.07$ in juvenile $v s$ $1.21 \pm 0.13$ in adult rats, $P=0.04)$. In addition, AMPAR-
EPSC in FS cells also exhibited significantly faster time constant decay, with an overall average of $4.45 \pm 0.33 \mathrm{~ms}$ $(P>0.05$ among groups), compared with $7.88 \pm 0.39 \mathrm{~ms}$ in RS and $8.00 \pm 0.49 \mathrm{~ms}$ in LTS cells $(P<0.0001$ for FS $v s$ RS and LTS). It should be noted, however, that although these currents are dominated by AMPARs at $-70 \mathrm{mV}$, they likely contain a component mediated by NMDARs that were not blocked in these recordings. Indeed, in experiments in which the NMDAR antagonist AP5 was applied to the bath solution, the 'pure' AMPAR-mediated currents recorded at $-70 \mathrm{mV}$ showed a significantly shorter time constant decay of $2-4 \mathrm{~ms}$, consistent with the findings from previous studies (Hestrin, 1993; Silver et al, 1996).

NMDAR-EPSCs in FS cells also showed a significantly shorter rise-time than those in RS and LTS cells, with an average of $2.39 \pm 0.13 \mathrm{~ms}$ in FS, $3.07 \pm 0.13 \mathrm{~ms}$ in RS, and $3.27 \pm 0.12 \mathrm{~ms}$ in LTS cells $(P<0.001$ for both; see Figure 4$)$. Unlike the AMPAR-EPSCs, the rise-time of NMDAR-EPSC in FS cells was age independent, without clear changes during cortical development $\left(R^{2}=0.053 ; P>0.05\right.$ among age groups). Nevertheless, the NMDA currents exhibited different time constant decays among the three cell types. In the juvenile animals (p15-28), the decay times in FS and RS cells were similar but significantly faster than those in LTS cells (see Table 1 for detail). The decay times of NMDA current in FS cells were age dependent, decreased dramatically to $21.6 \pm 3.05 \mathrm{~ms}$ in adults from $39.8 \pm 3.05 \mathrm{~ms}$ in juveniles $\left(R^{2}\right.$ of $\left.0.256 ; P<0.01\right)$. In contrast, there were almost no changes in RS, and a slight, but not significant, decrease in LTS cells $(P>0.05)$. Overall, the NMDA-EPSC in FS interneurons exhibited significantly faster decay times than those in RS and LTS cells, whereas the NMDA currents in LTS cells exhibited the slowest rate of decay $(31.5 \pm 3.20 \mathrm{~ms}$ in FS $v s \quad 44.3 \pm 2.10 \mathrm{~ms}$ in $\mathrm{RS}$ and $59.5 \pm 3.42 \mathrm{~ms}$ in LTS cells, $P<0.001$ in FS $v s$ RS and FS $v s$ LTS cells, $P<0.01$ between RS and LTS cells). The changes 

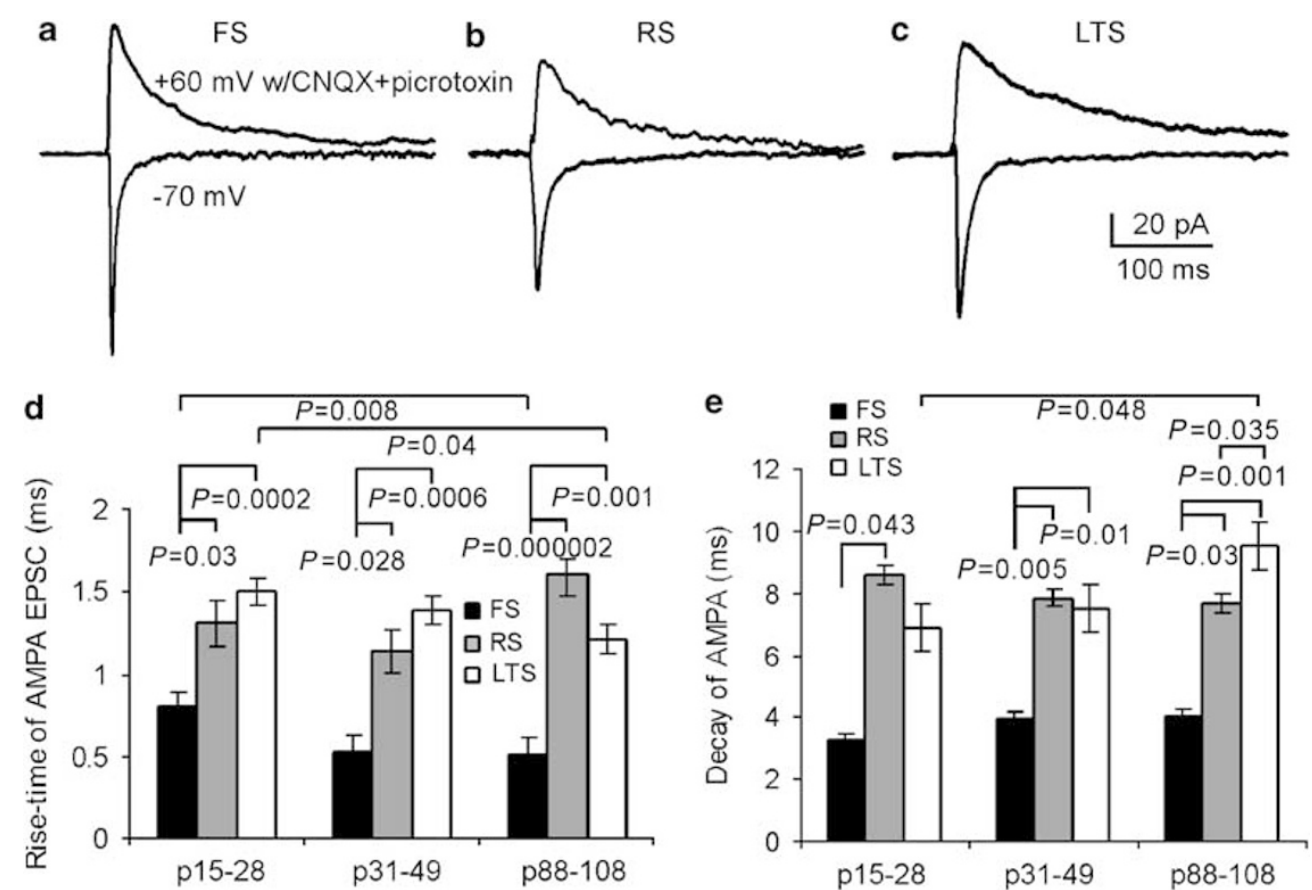

Figure 3 Properties of AMPAR-mediated currents in PFC interneurons. (a-c) Samples of AMPAR- and NMDAR-mediated currents recorded at -70 and $+60 \mathrm{mV}$, respectively, in the three cell types. (d) FS neurons exhibited significantly faster $(P<0.05)$ and age-dependent decrease $(P<0.0 \mathrm{I}$ between $\mathrm{pI} 5-28$ and p88-108) of rise-time (20-80\%). (e) FS cells show significantly faster decay than do RS and LTS neurons $(P<0.05)$. In contrast, changes in AMPARmediated current in RS and LTS cells are relatively small $(P>0.05)$, with LTS cells exhibiting significant difference only between pI5-28 and p88-108.
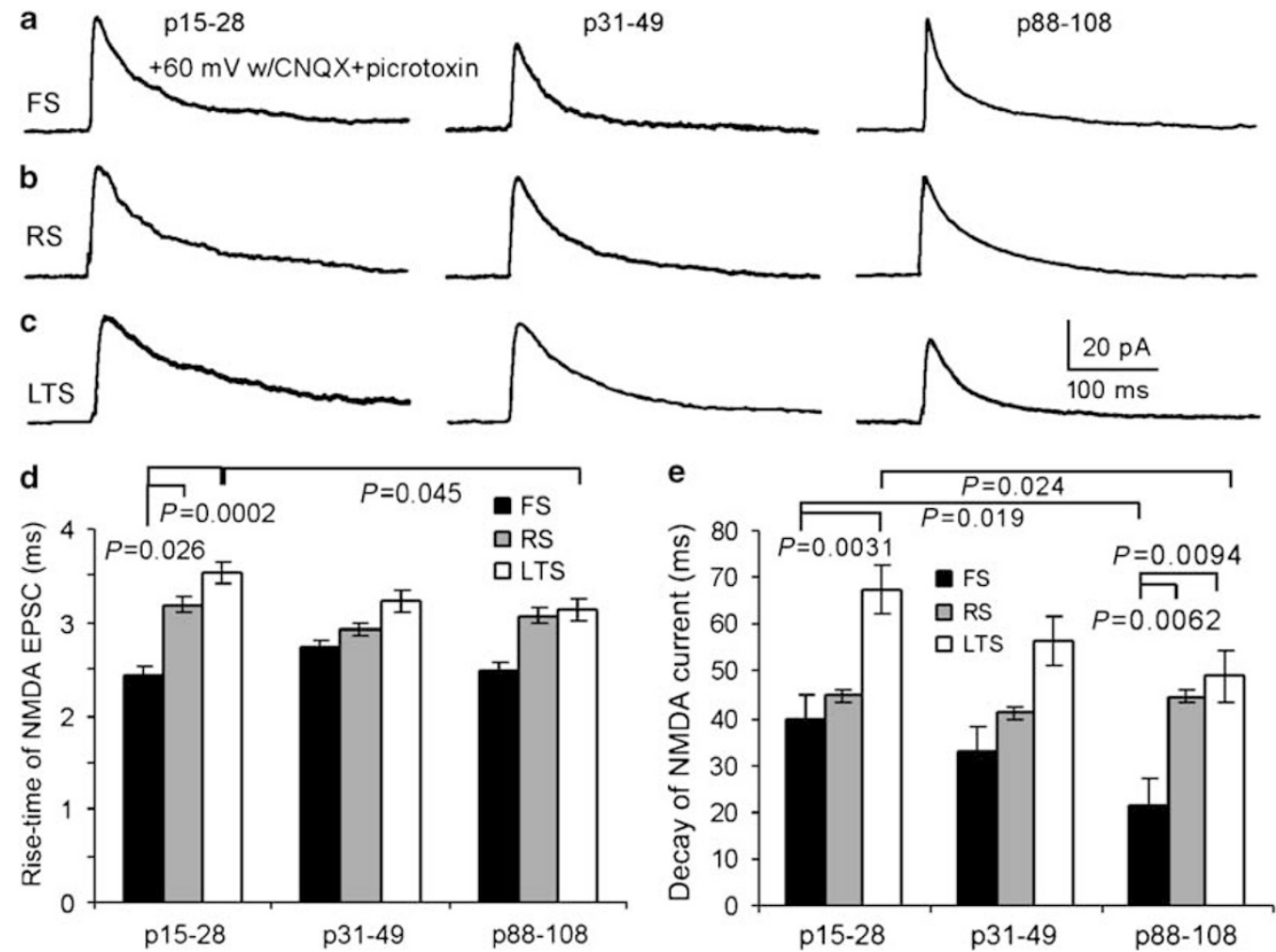

Figure 4 Properties of NMDAR-mediated currents in the PFC interneurons. (a-c) Samples of NMDAR-mediated currents in different cell types and age groups. (d) The 20-80\% rise-time of NMDAR-mediated currents was faster in the FS cells containing NMDARs than those in RS and LTS cells, but significance was observed only in p I5-28 rats $(P<0.05)$. (e) The time constant decays of FS cells were significantly (two-fold) faster $(P<0.003)$ than those of LTS cells but similar to those of RS cells in juvenile animals. The decays gradually decreased during cortical development and became significantly shorter $(P=0.0094)$ in adult animals, with an average decay time of $\sim 20 \mathrm{~ms}$. LTS cells showed similar decline of decays, with a significantly shorter time constant $(P=0.024)$ in adults than in juveniles. In contrast, the decays of RS cells were stable without significant change in all ages. 
in NMDAR-EPSC decays in the RS and LTS cells did not conform to the patterns reported previously in hippocampal neurons (Kirson and Yaari, 1996; Hsia et al, 1998), visual cortical neurons (Roberts and Ramoa, 1999), or superior collicular neurons (Hestrin, 1992). It was, however, similar to the PFC layer 5 pyramidal neurons (Wang et al, 2008) in that we did not find a maturational shortening in this property.

Because the NMDA/AMPA peak current ratio is probably a determinant of synaptic plasticity (Saal et al, 2003; Watt et al, 2004), we further compared the developmental changes of this ratio in the PFC interneurons. The NMDA/AMPA ratios in the three subtypes of interneurons recorded in all cortical layers were listed in Table 2. In contrast to the EPSC recorded in pyramidal neurons (Rumpel et al, 2004), the developmental changes of NMDA/AMPA ratios in most of the interneurons appeared to be laminar independent, with the exception of LTS cells, in which neurons in layer $2 / 3$ exhibited significantly higher NMDA/AMPA ratio than those in layer $1 \quad(P<0.05)$. Generally, FS interneurons showed the lowest and LTS cells the highest NMDA/AMPA ratio. They were, however, not significantly different due to the large variability among the different age groups and cell types $(P=0.631$ between FS and RS cells, $P=0.211$ between FS and LTS cells, and $P=0.172$ between RS and LTS cells; Figure 5). Nevertheless, it is interesting to note that the peak current ratio in FS neurons significantly decreased during the adolescent period from $0.90 \pm 0.19$ in juveniles to $0.33 \pm 0.12$ in adolescents $(P<0.05)$, and then increased to $0.77 \pm 0.20$ in adults. The dramatic change in the NMDA/AMPA ratio in FS interneurons is probably attributable to the significant

Table 2 Laminar Difference of NMDA/AMPA Ratio in the Three Subtypes of Interneurons

\begin{tabular}{lcll}
\hline & $\begin{array}{c}\text { FS with NMDA } \\
(\mathbf{n}=\mathbf{2 0})\end{array}$ & \multicolumn{1}{c}{$\mathbf{R S}(\boldsymbol{n}=\mathbf{3 7})$} & \multicolumn{1}{c}{ LTS $(\boldsymbol{n}=\mathbf{3 7})$} \\
\hline Layer I & $1.19(n=1)$ & $0.86 \pm 0.24(n=7)$ & $0.55 \pm 0.13(n=5)$ \\
Layer $2 / 3$ & $0.55 \pm 0.09(n=13)$ & $0.65 \pm 0.17(n=17)$ & $1.14 \pm 0.14(n=24) *$ \\
Layer 5 & $0.51 \pm 0.23(n=6)$ & $0.48 \pm 0.18(n=13)$ & $0.82 \pm 0.09(n=8)$ \\
\hline
\end{tabular}

* $P<0.05$ between layers $I$ and $2 / 3$ in LTS.

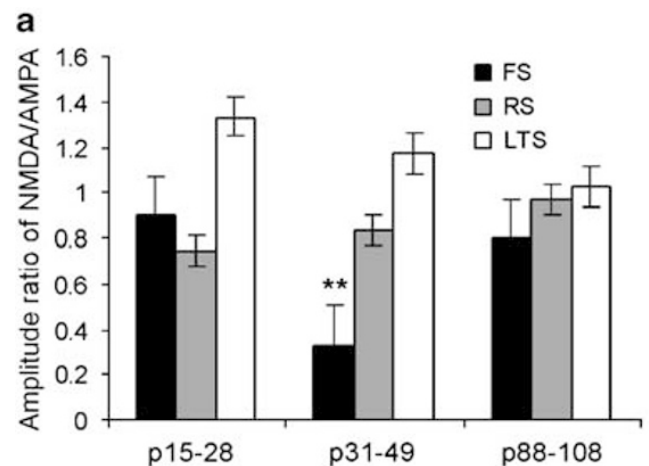

increase in AMPA currents in adolescents $(P<0.001)$, because NMDA currents appeared to be stable during development $(P>0.05$; Figure 5; Table 1$)$. In contrast, the NMDA/AMPA ratios in both RS and LTS interneurons were relatively unchanged during the period of prefrontal development, without significant difference $(P>0.05)$.

\section{FS Cells with NMDA Currents Exhibited Distinct Response to Ifenprodil}

Because NMDAR subunits are developmentally regulated (Monyer et al, 1994; Sheng et al, 1994; Liu et al, 2004), we tested the subunit ratio of NMDARs by applying selective NR2B antagonist ifenprodil ( $3 \mu \mathrm{M}$, bath) to perfusion media in prefrontal cortical preparations. Ifenprodil was previously reported to preferentially inhibit NR1/NR2B channels with 400 -fold higher affinity $\left(\mathrm{IC}_{50}=0.34 \mu \mathrm{M}\right)$ than NR1/NR2A channels $\left(\mathrm{IC}_{50}=146 \mu \mathrm{M}\right) \quad$ (Williams, 1993; Tovar and Westbrook, 1999). Our recent study also found that this chemical was able to block a large portion of NMDA currents in recurrent excitatory circuitry of prefrontal neurons in adult rats (Wang et al, 2008). We found that the amplitude of the synaptically evoked NMDAR-EPSCs in juvenile FS cells (p15-28) were significantly reduced by almost $70 \%$ but the changes were dramatically and significantly decreased to about $40 \%$ in adolescents and about $30 \%$ in adults $(P<0.05$; Figure 6$)$, suggesting a dramatic change of NMDAR subunits in FS cells in juveniles. In contrast, the NMDAR-EPSC amplitude changes in response to ifenprodil were relatively small $(\sim 50 \%)$ and stable in both RS and LTS cells, with only a slight change from juvenile to adult cells $(P>0.05$; Figure 6a and $b)$. To examine the effects of ifenprodil in NMDAREPSCs further, we have measured the time constant decays of the NMDAR-EPSCs before and after the ifenprodil application. As shown in Figure $6 \mathrm{c}$, we found that the NMDAR-EPSC decay was significantly decreased in juvenile FS cells only $(P<0.01)$, consistent with the significant effect in EPSC amplitude in the same age group (Figure 6b). Arguably, although ifenprodil was effective in reducing the EPSC amplitudes and shortening the EPSC decays in most of the interneurons tested, the differences in EPSC decays

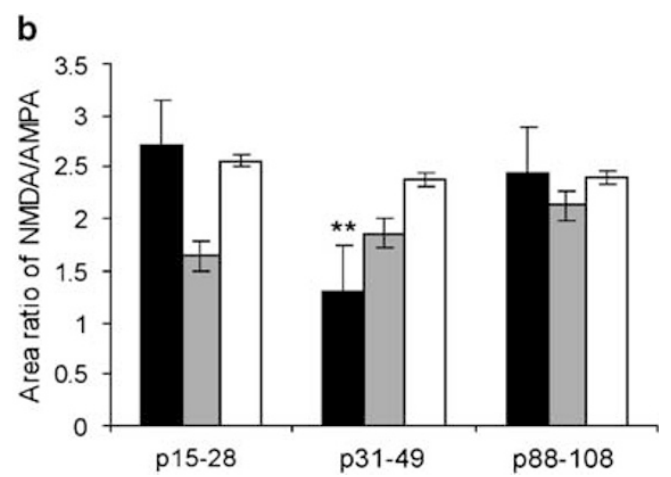

Figure 5 FS interneurons containing NMDARs exhibit distinct NMDAR/AMPAR-mediated current ratio and charge transfer in the adolescent period. $(a, b)$ The NMDA/AMPA ratio of peak amplitude and charge (integrated area). It is interesting that NMDA/AMPA ratios exhibit a very different trend among the three cell types. The FS cells undergo a dramatic reduction in the NMDA/AMPA ratio $(* * P<0.0 \mathrm{I})$, but this reduction is largely attributable to the high AMPAR-mediated current and a relatively small NMDA current. Compared with FS cells, RS and LTS cells show inverse trends in ratio changes, with gradual increase of ratio in RS but decrease in LTS, although not significant in both cell types. 

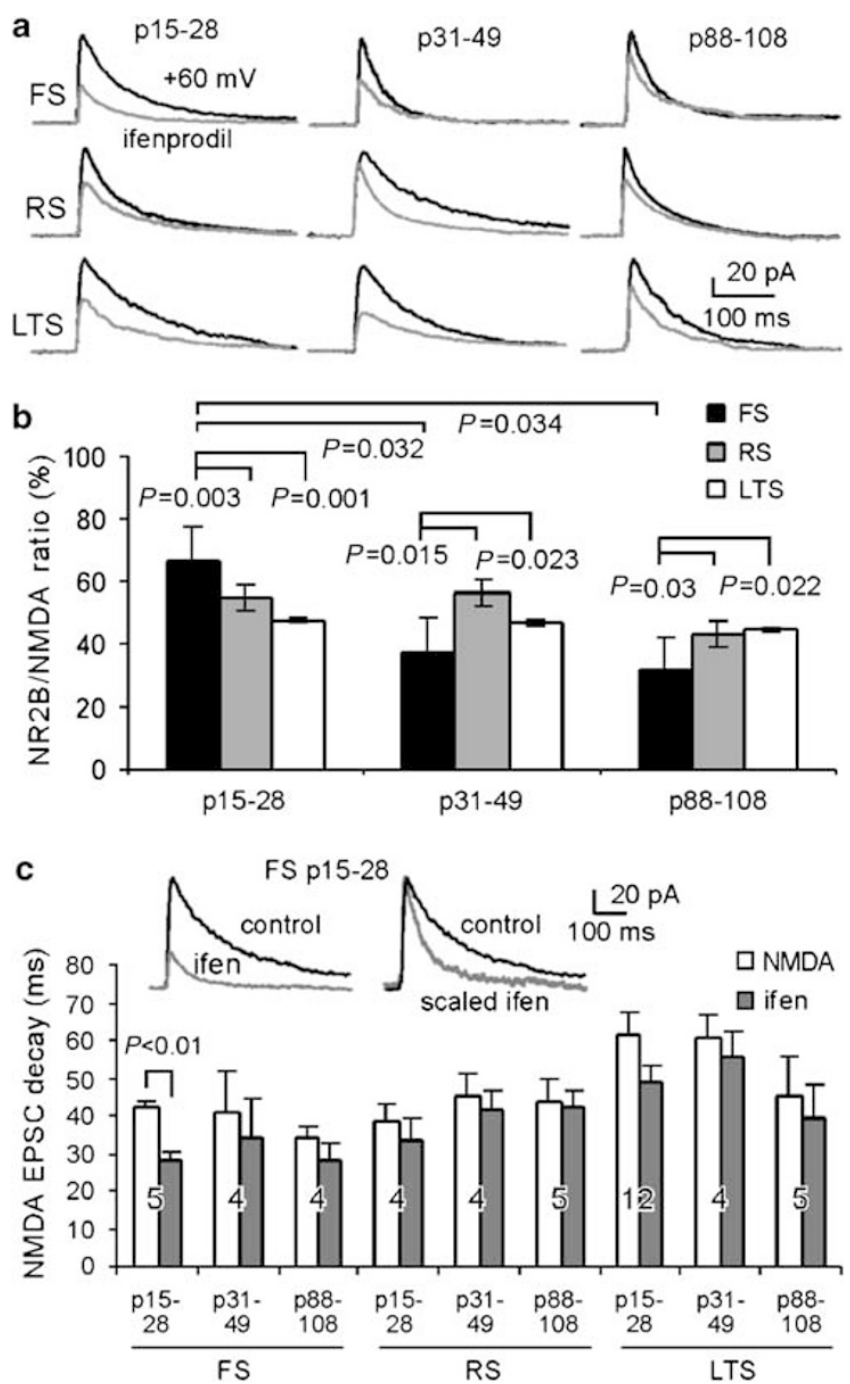

Figure 6 FS cells with NMDARs exhibit dramatic decline in NR2B subunits during development. (a) Samples of ifenprodil effects in NMDARmediated currents in three cell types in different age groups. NMDA currents in all three types of interneurons exhibit less sensitivity to ifenprodil in the adult. (b) Summary graph showing NMDA current sensitivity (\%) to ifenprodil. The sensitivity to ifenprodil gradually decreased during cortical development, with an average of $\sim 40 \%$ in adults, compared with $50-75 \%$ in juveniles. Significant differences were observed among the three cell types $(P<0.05)$. (c) Although ifenprodil was effective in shortening the EPSC decays in most of the interneurons tested, the differences in EPSC decays were not significant among the different age groups with the exception of juvenile (p|5-28) FS cells.

were not significant among the different age groups with the exception of juvenile FS cells. Similarly, in the monkey PFC layer 2/3 pyramidal neurons, Gonzalez-Burgos et al (2008) also reported that ifenprodil significantly decrease the NMDAR-EPSC amplitude (30-50\%) but had minimal effect in the EPSC decay (6-30\%). These data indicate that FS cells in the rat PFC may experience a developmental process of NMDAR subunit change different from other two cell types during the transition period from juvenile to adolescence.

\section{DISCUSSION}

To our knowledge, this study is the first systematic examination of NMDAR development in the cortical

interneurons. We found that most interneurons in the PFC express both NMDARs and AMPARs, with only onefourth of the FS cells expressing no synaptic NMDARs in juveniles. This conclusion is consistent with numerous previous studies that reported a limited role of NMDARmediated response in interneurons (Sah et al, 1990; Ling and Benardo, 1995; Thomson, 1997; Nyiri et al, 2003; Rotaru et al, 2008) and dominant $\mathrm{Ca}^{2+}$-permeable AMPARs in cortical FS interneurons (Goldberg et al, 2003; Wang and $\mathrm{Gao}, 2008)$. It is even more interesting that FS interneurons undergo remarkable changes during cortical development, particularly in adolescents, with $\sim 74 \%$ of the FS cells exhibiting no synaptic NMDAR-mediated currents in adult rat PFC. Even within the FS cells with NMDARs, the NMDA/ AMPA ratio was dramatically decreased in adolescents but returned to juvenile level in adults. In contrast, the expression of both AMPARs and NMDARs in the RS and LTS interneurons was relatively stable without appreciable changes during cortical development. This large variability of NMDARs in different subtypes of PFC interneurons is consistent with the findings from previous studies conducted in the neocortex (Goldberg et al, 2003) and hippocampus (Sah et al, 1990; Lei and McBain, 2002; Maccaferri and Dingledine, 2002; Nyiri et al, 2003). McBain and Dingledine (1993) proposed that certain interneurons in the hippocampus might use calcium-permeable AMPARs to compensate for the apparent lack of synaptic NMDARs. Our finding that some FS interneurons have no NMDARs is in line with this proposition. Indeed, hippocampal interneurons expressing calcium-permeable (or GluR2-lacking) AMPARs exhibited NMDAR-independent long-term depression (Laezza et al, 1999), whereas in interneurons expressing calcium-impermeable (or GluR2-containing) AMPARs, the induction of long-term depression was NMDAR dependent (Lei and McBain, 2002, 2004; Lu et al, 2007). Whether this principle can be applied to the FS interneurons with and without NMDARs in the PFC remains to be explored. It is possible that FS interneurons expressing NMDARs exhibit more NR2B subunits in juveniles (Plant et al, 1997) but an abrupt subunit switch occurs during prefrontal cortical development, leading to more NR2A subunits by the time adolescence and adulthood are reached. In contrast, FS interneurons expressing no NMDARs may be gradually replaced with calciumpermeable AMPARs during development (Wang and Gao, 2008).

Previous studies indicated that NR2B expression is highest at birth, whereas NR2A is not expressed until around p7 (Monyer et al, 1994). NMDARs at early stage of the development in the forebrain are therefore mainly composed of NR1/NR2B. As NR2A levels increase during neuronal maturation, synaptic NR1/NR2B receptors are gradually replaced by NR2A-containing NMDARs (Tovar and Westbrook, 1999; Philpot et al, 2001; Barria and Malinow, 2002), which may be pure NR1/NR2A or the triheteromer NR1/NR2A/NR2B (Sheng et al, 1994; Luo et al, 1997; Li et al, 2004). In the present study, we found that ifenprodil, a high-affinity selective inhibitor of NR1/NR2B diheteromeric NMDARs, blocked the NMDAR-EPSC amplitudes by $30-50 \%$ in most of the interneurons examined except for the juvenile FS cells $(\sim 70 \%)$. This was considerably less than the $\sim 80 \%$ blockade found in cells 
that express only recombinant NR1/NR2B receptors (Tovar and Westbrook, 1999). Furthermore, we found that ifenprodil did not significantly alter the decay of the synaptically evoked NMDAR-EPSCs in most of the interneurons tested with the exception of FS cells in juveniles. This was similar to the numerous previous findings reported in monkey layer 3 pyramidal neurons (GonzalezBurgos et al, 2008), rat visual cortical neurons (Yoshimura et al, 2003), mice CA1 pyramidal cells (Kirson and Yaari, 1996), rat dentate gyrus granule cells (Ye et al, 2005), and neocortical pyramidal cells (Kumar and Huguenard, 2003). That is, a significant decrease in NMDAR-EPSC amplitude occurs, but with minimal effect on the decay in response to ifenprodil. It is, however, apparently at odds with our recent report in recurrent connections between layer 5 pyramidal neurons, in which both NMDAR-EPSC amplitude and time constant decay were significantly decreased by ifenprodil (Wang et al, 2008). It also differed from observations obtained from cultured dissociated cells derived from young $\mathrm{CA} 1$ as well as recombinant NR1/NR2B receptors in which ifenprodil markedly shortened decay times of NMDA currents (Tovar and Westbrook, 1999) and many other studies (Chen et al, 1999; Lei and McBain, 2002). The reason for these differences remains unknown but an afferent-specific difference of NMDA response to ifenprodil was reported (Kumar and Huguenard, 2003; Szinyei et al, 2003). It is also possible that the composition of NMDAR subunits distributed in the layer 5 pyramidal neurons differs from the layer 2/3 pyramidal neurons (GonzalezBurgos et al, 2008; Wang et al, 2008) and pyramidal neurons in other cortical regions (Kirson and Yaari, 1996; Kumar and Huguenard, 2003; Yoshimura et al, 2003; Ye et al, 2005). Furthermore, as native NMDARs are typically diheteromers composed of NR1 and single NR2 isoforms (Banke and Traynelis, 2003), the relative ifenprodil insensitivity in our data suggests that triheteromeric receptors NR1/NR2A/ NR2B or other subunit combinations (eg, NR1/NR2A/ NR2D) might shape the decay of NMDAR-EPSCs in most of the PFC interneurons except juvenile FS cells. Whether this is the case remains to be tested because the effect of ifenprodil on triheteromeric receptors is not clear (Brimecombe et al, 1997; Vicini et al, 1998; Li et al, 2004; Bellone and Nicoll, 2007). Hatton and Paoletti (2005) suggest that triheteromeric receptors have a high affinity for ifenprodil but are inhibited to only a small extent. Nevertheless, it would be interesting in the future to determine whether the triheteromeric NR1/NR2A/NR2B contributes to the synaptic currents in PFC interneurons (Donevan and McCabe, 2000; Li et al, 2004).

\section{Functional Implications of Synaptic NMDARs on PFC Interneurons}

GABAergic interneurons are essential not only for normal synchronous activity (Somogyi et al, 1998; McBain and Fisahn, 2001; Buzsaki et al, 2007) but also for desynchronization of gamma band oscillations in schizophrenia (Whittington et al, 2000; Spencer et al, 2003, 2004; Cunningham et al, 2006; Uhlhaas and Singer, 2006). NMDARs, however, play an essential role in controlling the integrative properties of interneurons (Maccaferri and Dingledine, 2002). Our findings indicate that FS interneur- ons, the most important inhibitory cells in the neocortex, undergo dramatic changes in glutamatergic receptors during the juvenile and adolescent periods, with a sharp decrease in the NMDA/AMPA ratio and the gradual loss of NMDARs. Because FS interneurons exhibit powerful perisomatic inhibitory activity in pyramidal neurons (Galarreta and Hestrin, 2001; Pouille and Scanziani, 2001; Gao et al, 2003; Hasenstaub et al, 2005), dramatic changes of NMDA and AMPA receptors in FS cells would have significant effect on neuronal synchronous activity (Cunningham et al, 2006). Disruption of NMDARs during the adolescent period would be crucial for the onset of many psychiatric disorders, including schizophrenia (Lewis et al, 2005). Indeed, previous studies indicate that certain markers such as parvalbumin for FS interneurons in the PFC exhibit striking changes during adolescence and that these neurons are markedly altered in the PFC of subjects with schizophrenia (Reynolds and Beasley, 2001; Lewis et al, 2004). This seems to fit well with the selective damage of a sub-population of interneurons in the PFC in patients with schizophrenia (Benes et al, 1991; Beasley and Reynolds, 1997; Volk et al, 2000; Benes and Berretta, 2001; Hashimoto et al, 2003; Lewis et al, 2005). On the other hand, NMDARdependent integration of synaptic input in different interneurons could also be involved in several situations that require time-prolonged firing during asynchronous activity. For example, delayed-period activity, which is believed to be the neuronal correlate of working memory (Fuster and Alexander, 1971; Goldman-Rakic, 1995), is thought to depend crucially on synaptic kinetics of NMDA currents in prefrontal microcircuits (Wang, 1999, 2001; Durstewitz and Gabriel, 2007; Wang et al, 2008). Because only one-fourth of the FS cells in adults contain synaptic NMDARs, even a small change in NMDARs, such as NMDAR hypofunction occurring in schizophrenia, could have dramatic effect on prefrontal functions (Homayoun and Moghaddam, 2007). In summary, the dramatic changes of NMDARs in FS interneurons in adolescence may make FS cells particularly sensitive and vulnerable to detrimental stimulations such as traumatic stress and drug addiction, thus contributing to the onset of many psychiatric disorders, including schizophrenia.

\section{ACKNOWLEDGEMENTS}

We thank Drs Guillermo Gonzalez-Burgos, Melanie Alexander, Ms Kimberly Urban for comments on the paper, and Ms Pamela Fried for editorial work. This study was supported by a grant from Drexel University College of Medicine, NARSAD young investigator awards, and $\mathrm{Na-}$ tional Institutes of Health (NIH) R21 grant MH232307 to W-J Gao. The NIH had no further role in the study design; in the collection, analysis, and interpretation of the data; in the writing of the report; or in the decision to submit the paper for publication.

\section{DISCLOSURE/CONFLICT OF INTEREST}

The authors declared no conflict of interest. 


\section{REFERENCES}

Angulo MC, Rossier J, Audinat E (1999). Postsynaptic glutamate receptors and integrative properties of fast-spiking interneurons in the rat neocortex. J Neurophysiol 82: 1295-1302.

Angulo MC, Lambolez B, Audinat E, Hestrin S, Rossier J (1997). Subunit composition, kinetic, and permeation properties of AMPA receptors in single neocortical nonpyramidal cells. J Neurosci 17: 6685-6696.

Banke TG, Traynelis SF (2003). Activation of NR1/NR2B NMDA receptors. Nat Neurosci 6: 144-152.

Barria A, Malinow R (2002). Subunit-specific NMDA receptor trafficking to synapses. Neuron 35: 345-353.

Beasley CL, Reynolds GP (1997). Parvalbumin-immunoreactive neurons are reduced in the prefrontal cortex of schizophrenics. Schizophr Res 24: 349-355.

Behrens MM, Ali SS, Dao DN, Lucero J, Shekhtman G, Quick KL et al (2007). Ketamine-induced loss of phenotype of fast-spiking interneurons is mediated by NADPH-oxidase. Science 318: 1645-1647.

Bellone C, Nicoll RA (2007). Rapid bidirectional switching of synaptic NMDA receptors. Neuron 55: 779-785.

Benes FM, Berretta S (2001). GABAergic interneurons: implications for understanding schizophrenia and bipolar disorder. Neuropsychopharmacology 25: 1-27.

Benes FM, McSparren J, Bird ED, SanGiovanni JP, Vincent SL (1991). Deficits in small interneurons in prefrontal and cingulate cortices of schizophrenic and schizoaffective patients. Arch Gen Psychiatry 48: 996-1001.

Beneyto M, Meador-Woodruff JH (2008). Lamina-specific abnormalities of NMDA receptor-associated postsynaptic protein transcripts in the prefrontal cortex in schizophrenia and bipolar disorder. Neuropsychopharmacology 33: 2175-2186.

Blatow M, Caputi A, Monyer H (2005). Molecular diversity of neocortical GABAergic interneurones. J Physiol 562: 99-105.

Brimecombe JC, Boeckman FA, Aizenman E (1997). Functional consequences of NR2 subunit composition in single recombinant $N$-methyl-D-aspartate receptors. Proc Natl Acad Sci USA 94: 11019-11024.

Buzsaki G, Kaila K, Raichle M (2007). Inhibition and brain work. Neuron 56: 771-783.

Chen N, Luo T, Raymond LA (1999). Subtype-dependence of NMDA receptor channel open probability. J Neurosci 19: 6844-6854.

Coyle JT (2006). Glutamate and schizophrenia: beyond the dopamine hypothesis. Cell Mol Neurobiol 26: 365-384.

Cunningham MO, Hunt J, Middleton S, LeBeau FE, Gillies MJ, Davies CH et al (2006). Region-specific reduction in entorhinal gamma oscillations and parvalbumin-immunoreactive neurons in animal models of psychiatric illness. J Neurosci 26: 2767-2776.

Donevan SD, McCabe RT (2000). Conantokin G is an NR2Bselective competitive antagonist of $N$-methyl-D-aspartate receptors. Mol Pharmacol 58: 614-623.

Durstewitz D, Gabriel T (2007). Dynamical basis of irregular spiking in NMDA-driven prefrontal cortex neurons. Cereb Cortex 17: 894-908.

Freund TF, Buzsaki G (1996). Interneurons of the hippocampus. Hippocampus 6: 347-470.

Fuster JM, Alexander GE (1971). Neuron activity related to shortterm memory. Science 173: 652-654.

Galarreta M, Hestrin S (2001). Spike transmission and synchrony detection in networks of GABAergic interneurons. Science 292: 2295-2299.

Gao WJ (2007). Acute clozapine suppresses synchronized pyramidal synaptic network activity by increasing inhibition in the ferret prefrontal cortex. J Neurophysiol 97: 1196-1208.
Gao WJ, Goldman-Rakic PS (2003). Selective modulation of excitatory and inhibitory microcircuits by dopamine. Proc Natl Acad Sci USA 100: 2836-2841.

Gao WJ, Krimer LS, Goldman-Rakic PS (2001). Presynaptic regulation of recurrent excitation by $\mathrm{D} 1$ receptors in prefrontal circuits. Proc Natl Acad Sci USA 98: 295-300.

Gao WJ, Wang Y, Goldman-Rakic PS (2003). Dopamine modulation of perisomatic and peridendritic inhibition in prefrontal cortex. J Neurosci 23: 1622-1630.

Gao WJ, Wormington AB, Newman DE, Pallas SL (2000). Development of inhibitory circuitry in visual and auditory cortex of postnatal ferrets: immunocytochemical localization of calbindin- and parvalbumin-containing neurons. J Comp Neurol 422: $140-157$.

Gibson JR, Beierlein M, Connors BW (1999). Two networks of electrically coupled inhibitory neurons in neocortex. Nature 402: 75-79.

Goldberg JH, Yuste R, Tamas G (2003). $\mathrm{Ca}^{2+}$ imaging of mouse neocortical interneuron dendrites: contribution of $\mathrm{Ca}^{2+}$-permeable AMPA and NMDA receptors to subthreshold $\mathrm{Ca}^{2+}$ dynamics. J Physiol 551: 67-78.

Goldman-Rakic PS (1995). Cellular basis of working memory. Neuron 14: 477-485.

Gonzalez-Burgos G, Kroener S, Zaitsev AV, Povysheva NV, Krimer LS, Barrionuevo $G$ et al (2008). Functional maturation of excitatory synapses in layer 3 pyramidal neurons during postnatal development of the primate prefrontal cortex. Cereb Cortex 18: 626-637.

Harte MK, Powell SB, Swerdlow NR, Geyer MA, Reynolds GP (2007). Deficits in parvalbumin and calbindin immunoreactive cells in the hippocampus of isolation reared rats. J Neural Transm 114: 893-898.

Hasenstaub A, Shu Y, Haider B, Kraushaar U, Duque A, McCormick DA (2005). Inhibitory postsynaptic potentials carry synchronized frequency information in active cortical networks. Neuron 47: 423-435.

Hashimoto T, Volk DW, Eggan SM, Mirnics K, Pierri JN, Sun Z et al (2003). Gene expression deficits in a subclass of GABA neurons in the prefrontal cortex of subjects with schizophrenia. J Neurosci 23: 6315-6326.

Hatton CJ, Paoletti P (2005). Modulation of triheteromeric NMDA receptors by N-terminal domain ligands. Neuron 46: 261-274.

Hestrin S (1992). Developmental regulation of NMDA receptormediated synaptic currents at a central synapse. Nature 357: 686-689.

Hestrin S (1993). Different glutamate receptor channels mediate fast excitatory synaptic currents in inhibitory and excitatory cortical neurons. Neuron 11: 1083-1091.

Homayoun H, Moghaddam B (2007). NMDA receptor hypofunction produces opposite effects on prefrontal cortex interneurons and pyramidal neurons. J Neurosci 27: 11496-11500.

Hsia AY, Malenka RC, Nicoll RA (1998). Development of excitatory circuitry in the hippocampus. J Neurophysiol 79: 2013-2024.

Javitt DC, Zukin SR (1991). Recent advances in the phencyclidine model of schizophrenia. Am J Psychiatry 148: 1301-1308.

Kawaguchi Y (1995). Physiological subgroups of nonpyramidal cells with specific morphological characteristics in layer II/III of rat frontal cortex. J Neurosci 15: 2638-2655.

Kinney JW, Davis CN, Tabarean I, Conti B, Bartfai T, Behrens MM (2006). A specific role for NR2A-containing NMDA receptors in the maintenance of parvalbumin and GAD67 immunoreactivity in cultured interneurons. J Neurosci 26: 1604-1615.

Kirson ED, Yaari Y (1996). Synaptic NMDA receptors in developing mouse hippocampal neurones: functional properties and sensitivity to ifenprodil. $J$ Physiol 497(Part 2): 437-455.

Koh DS, Geiger JR, Jonas P, Sakmann B (1995). Ca(2+)-permeable AMPA and NMDA receptor channels in basket cells of rat hippocampal dentate gyrus. J Physiol 485(Part 2): 383-402. 
Kristiansen LV, Beneyto M, Haroutunian V, Meador-Woodruff JH (2006). Changes in NMDA receptor subunits and interacting PSD proteins in dorsolateral prefrontal and anterior cingulate cortex indicate abnormal regional expression in schizophrenia. Mol Psychiatry 11: 737-747.

Kristiansen LV, Huerta I, Beneyto M, Meador-Woodruff JH (2007). NMDA receptors and schizophrenia. Curr Opin Pharmacol 7: 48-55.

Krystal JH, Karper LP, Seibyl JP, Freeman GK, Delaney R, Bremner JD et al (1994). Subanesthetic effects of the noncompetitive NMDA antagonist, ketamine, in humans. Psychotomimetic, perceptual, cognitive, and neuroendocrine responses. Arch Gen Psychiatry 51: 199-214.

Kumar SS, Huguenard JR (2003). Pathway-specific differences in subunit composition of synaptic NMDA receptors on pyramidal neurons in neocortex. J Neurosci 23: 10074-10083.

Laezza F, Doherty JJ, Dingledine R (1999). Long-term depression in hippocampal interneurons: joint requirement for pre- and postsynaptic events. Science 285: 1411-1414.

Lahti AC, Koffel B, LaPorte D, Tamminga CA (1995). Subanesthetic doses of ketamine stimulate psychosis in schizophrenia. Neuropsychopharmacology 13: 9-19.

Lei S, McBain CJ (2002). Distinct NMDA receptors provide differential modes of transmission at mossy fiber-interneuron synapses. Neuron 33: 921-933.

Lei S, McBain CJ (2004). Two Loci of expression for long-term depression at hippocampal mossy fiber-interneuron synapses. J Neurosci 24: 2112-2121.

Lewis DA, Gonzalez-Burgos G (2008). Neuroplasticity of neocortical circuits in schizophrenia. Neuropsychopharmacology 33: 141-165.

Lewis DA, Cruz D, Eggan S, Erickson S (2004). Postnatal development of prefrontal inhibitory circuits and the pathophysiology of cognitive dysfunction in schizophrenia. Ann NY Acad Sci 1021: 64-76.

Lewis DA, Hashimoto T, Volk DW (2005). Cortical inhibitory neurons and schizophrenia. Nat Rev Neurosci 6: 312-324.

Li L, Murphy TH, Hayden MR, Raymond LA (2004). Enhanced striatal NR2B-containing N-Methyl-D-aspartate receptormediated synaptic currents in a mouse model of Huntington disease. J Neurophysiol 92: 2738-2746.

Lindsley CW, Shipe WD, Wolkenberg SE, Theberge CR, Williams Jr DL, Sur C et al (2006). Progress towards validating the NMDA receptor hypofunction hypothesis of schizophrenia. Curr Top Med Chem 6: 771-785.

Ling DS, Benardo LS (1995). Recruitment of GABAA inhibition in rat neocortex is limited and not NMDA dependent. J Neurophysiol 74: 2329-2335.

Liu XB, Murray KD, Jones EG (2004). Switching of NMDA receptor $2 \mathrm{~A}$ and $2 \mathrm{~B}$ subunits at thalamic and cortical synapses during early postnatal development. J Neurosci 24: 8885-8895.

Lu J-T, Li C-Y, Zhao J-P, Poo M-M, Zhang X-H (2007). Spiketiming-dependent plasticity of neocortical excitatory synapses on inhibitory interneurons depends on target cell type. J Neurosci 27: 9711-9720.

Luo J, Wang Y, Yasuda RP, Dunah AW, Wolfe BB (1997). The majority of $N$-methyl-D-aspartate receptor complexes in adult rat cerebral cortex contain at least three different subunits (NR1/ NR2A/NR2B). Mol Pharmacol 51: 79-86.

Maccaferri G, Dingledine R (2002). Control of feedforward dendritic inhibition by NMDA receptor-dependent spike timing in hippocampal interneurons. J Neurosci 22: 5462-5472.

Markram H, Toledo-Rodriguez M, Wang Y, Gupta A, Silberberg G, $\mathrm{Wu} C$ (2004). Interneurons of the neocortical inhibitory system. Nat Rev Neurosci 5: 793-807.

McBain CJ, Dingledine R (1993). Heterogeneity of synaptic glutamate receptors on CA3 stratum radiatum interneurones of rat hippocampus. J Physiol 462: 373-392.
McBain CJ, Fisahn A (2001). Interneurons unbound. Nat Rev Neurosci 2: 11-23.

Moghaddam B, Jackson ME (2003). Glutamatergic animal models of schizophrenia. Ann NY Acad Sci 1003: 131-137.

Mohn AR, Gainetdinov RR, Caron MG, Koller BH (1999). Mice with reduced NMDA receptor expression display behaviors related to schizophrenia. Cell 98: 427-436.

Monyer H, Burnashev N, Laurie DJ, Sakmann B, Seeburg PH (1994). Developmental and regional expression in the rat brain and functional properties of four NMDA receptors. Neuron 12: 529-540.

Morin F, Beaulieu C, Lacaille JC (1996). Membrane properties and synaptic currents evoked in CA1 interneuron subtypes in rat hippocampal slices. J Neurophysiol 76: 1-16.

Morris BJ, Cochran SM, Pratt JA (2005). PCP: from pharmacology to modelling schizophrenia. Curr Opin Pharmacol 5: 101-106.

Nyiri G, Freund TF, Somogyi P (2001). Input-dependent synaptic targeting of alpha(2)-subunit-containing GABA(A) receptors in synapses of hippocampal pyramidal cells of the rat. Eur $J$ Neurosci 13: 428-442.

Nyiri G, Stephenson FA, Freund TF, Somogyi P (2003). Large variability in synaptic $N$-methyl-D-aspartate receptor density on interneurons and a comparison with pyramidal-cell spines in the rat hippocampus. Neuroscience 119: 347-363.

Olney JW, Farber NB (1995). Glutamate receptor dysfunction and schizophrenia. Arch Gen Psychiatry 52: 998-1007.

Perouansky M, Yaari Y (1993). Kinetic properties of NMDA receptor-mediated synaptic currents in rat hippocampal pyramidal cells versus interneurones. J Physiol 465: 223-244.

Philpot BD, Sekhar AK, Shouval HZ, Bear MF (2001). Visual experience and deprivation bidirectionally modify the composition and function of NMDA receptors in visual cortex. Neuron 29: 157-169.

Plant T, Schirra C, Garaschuk O, Rossier J, Konnerth A (1997). Molecular determinants of NMDA receptor function in GABAergic neurones of rat forebrain. J Physiol 499(Part 1): 47-63.

Pouille F, Scanziani M (2001). Enforcement of temporal fidelity in pyramidal cells by somatic feed-forward inhibition. Science 293: $1159-1163$.

Reynolds GP, Beasley CL (2001). GABAergic neuronal subtypes in the human frontal cortex--development and deficits in schizophrenia. J Chem Neuroanat 22: 95-100.

Roberts EB, Ramoa AS (1999). Enhanced NR2A subunit expression and decreased NMDA receptor decay time at the onset of ocular dominance plasticity in the ferret. J Neurophysiol 81: 2587-2591.

Rotaru DC, Povysheva NV, Zaitsev AV, Krimer LS, Lewis DA, Gonzalez-Burgos G (2008). Functional properties of GABA synapses onto different interneuron classes in the monkey dorsolateral prefrontal cortex.. Soc Neurosci 531: 519.

Rujescu D, Bender A, Keck M, Hartmann AM, Ohl F, Raeder H et al (2006). A pharmacological model for psychosis based on $\mathrm{N}$-methyl-D-aspartate receptor hypofunction: molecular, cellular, functional and behavioral abnormalities. Biol Psychiatry 59: 721-729.

Rumpel S, Kattenstroth G, Gottmann K (2004). Silent synapses in the immature visual cortex: layer-specific developmental regulation. J Neurophysiol 91: 1097-1101.

Saal D, Dong Y, Bonci A, Malenka RC (2003). Drugs of abuse and stress trigger a common synaptic adaptation in dopamine neurons. Neuron 37: 577-582.

Sah P, Hestrin S, Nicoll RA (1990). Properties of excitatory postsynaptic currents recorded in vitro from rat hippocampal interneurones. J Physiol 430: 605-616.

Sheng M, Cummings J, Roldan LA, Jan YN, Jan LY (1994). Changing subunit composition of heteromeric NMDA receptors during development of rat cortex. Nature 368: 144-147.

Silver RA, Colquhoun D, Cull-Candy SG, Edmonds B (1996). Deactivation and desensitization of non-NMDA receptors in 
patches and the time course of EPSCs in rat cerebellar granule cells. J Physiol 493(Part 1): 167-173.

Somogyi P, Tamas G, Lujan R, Buhl EH (1998). Salient features of synaptic organisation in the cerebral cortex. Brain Res Brain Res Rev 26: 113-135.

Spear LP (2000). The adolescent brain and age-related behavioral manifestations. Neurosci Biobehav Rev 24: 417-463.

Spencer KM, Nestor PG, Niznikiewicz MA, Salisbury DF, Shenton ME, McCarley RW (2003). Abnormal neural synchrony in schizophrenia. J Neurosci 23: 7407-7411.

Spencer KM, Nestor PG, Perlmutter R, Niznikiewicz MA, Klump MC, Frumin M et al (2004). Neural synchrony indexes disordered perception and cognition in schizophrenia. Proc Natl Acad Sci USA 101: 17288-17293.

Szinyei C, Stork O, Pape HC (2003). Contribution of NR2B subunits to synaptic transmission in amygdaloid interneurons. $J$ Neurosci 23: 2549-2556.

Thomson AM (1997). Activity-dependent properties of synaptic transmission at two classes of connections made by rat neocortical pyramidal axons in vitro. J Physiol 502: 131-147.

Tovar KR, Westbrook GL (1999). The incorporation of NMDA receptors with a distinct subunit composition at nascent hippocampal synapses in vitro. J Neurosci 19: 4180-4188.

Tseng KY, O’Donnell P (2007). Dopamine modulation of prefrontal cortical interneurons changes during adolescence. Cereb Cortex 17: $1235-1240$.

Uhlhaas PJ, Singer W (2006). Neural synchrony in brain disorders: relevance for cognitive dysfunctions and pathophysiology. Neuron 52: 155-168.

Vicini S, Wang JF, Li JH, Zhu WJ, Wang YH, Luo JH et al (1998). Functional and pharmacological differences between recombinant $N$-methyl-D-aspartate receptors. J Neurophysiol 79: 555-566.

Volk DW, Austin MC, Pierri JN, Sampson AR, Lewis DA (2000). Decreased glutamic acid decarboxylase67 messenger RNA expression in a subset of prefrontal cortical gamma-aminobutyric acid neurons in subjects with schizophrenia. Arch Gen Psychiatry 57: 237-245.
Wang H, Gao W (2008). Distinct physiological properties of calcium-permeable AMPA receptors in fast spiking interneurons of rat prefrontal cortex. Soc Neurosci: 130: 114.

Wang H, Stradtman GGR, Wang XJ, Gao WJ (2008). A specialized NMDA receptor function in layer 5 recurrent microcircuitry of the adult rat prefrontal cortex. Proc Natl Acad Sci USA 105: 16791-16796.

Wang X-J (1999). Synaptic basis of cortical persistent activity: the importance of NMDA receptors to working memory. J Neurosci 19: 9587-9603.

Wang X-J (2001). Synaptic reverberation underlying mnemonic persistent activity. Trends Neurosci 24: 455-463.

Watt AJ, Sjostrom PJ, Hausser M, Nelson SB, Turrigiano GG (2004). A proportional but slower NMDA potentiation follows AMPA potentiation in LTP. Nat Neurosci 7: 518-524.

Whittington MA, Faulkner HJ, Doheny HC, Traub RD (2000). Neuronal fast oscillations as a target site for psychoactive drugs. Pharmacol Ther 86: 171-190.

Whittington MA, Traub RD (2003). Interneuron diversity series: inhibitory interneurons and network oscillations in vitro. Trends Neurosci 26: 676-682.

Williams K (1993). Ifenprodil discriminates subtypes of the $\mathrm{N}$-methyl-D-aspartate receptor: selectivity and mechanisms at recombinant heteromeric receptors. Mol Pharmacol 44: 851-859.

Xiang Z, Huguenard JR, Prince DA (1998). Cholinergic switching within neocortical inhibitory networks. Science 281: 985-988.

Ye GL, Yi S, Gamkrelidze G, Pasternak JF, Trommer BL (2005). AMPA and NMDA receptor-mediated currents in developing dentate gyrus granule cells. Brain Res Dev Brain Res 155: 26-32.

Yoshimura Y, Ohmura T, Komatsu Y (2003). Two forms of synaptic plasticity with distinct dependence on age, experience, and NMDA receptor subtype in rat visual cortex. J Neurosci 23: 6557-6566.

Zhou FM, Hablitz JJ (1998). AMPA receptor-mediated EPSCs in rat neocortical layer II/III interneurons have rapid kinetics. Brain Res 780: 166-169. 